\title{
Sosialisasi Masyarakat Tentang Sub Aliran Sungai Di Sekitar Kawasan Hutan Kampung Klaben Distrik Mariat Gunung Kabupaten Sorong
}

\author{
Irnawati $^{1}$, Nur Hidaya ${ }^{2}$ \\ ${ }^{1}$ Fakultas Pertanian, Universitas Muhammadiyah Sorong, Indonesia \\ ${ }^{2}$ Fakultas Ilmu Social dan Politik, Universitas Muhammadiyah Sorong, Indonesia \\ *E-mail: irnawatif@gmail.com
}

\begin{abstract}
ABSTRAK
Sosialisasi Masyarakat Kampung Klaben dengan melihat langsung kemasyarakat local tentang Sikap Masyarakat terhadap Pemberdayaan masyarakat dalam pengelolaan DAS, perlu diketahui tujuan dari sosialisasi ini mengetahui kondisi Sosial ekonomi Masyarakat terhadap sumberdaya alam di Sekitar Di Sub Das. Metode yang di gunakan dalam pengabdian ini adalah penyuluhan pada tingkat masyarakat dengan data yang mencakup deskriptif yang menggambarkan suatu kondisi alam masyarakat terhadap Pengelolaan daerah aliran sungai, Sehingga Hasil dari sosialisasi langsung ke masyarakat local yang aktif melakukan perkebunan dan mengambil kayu bakar di pinggiran sungai sebagai kebutuhan hidup, dan mengajak masyarakat untuk ikut terlibat dalam kegiatan penanaman 1000 pohon pada pinggiran sungai. Kesimpulan yang didapat adalah Masyarakat sekitar das menunjukkan bahwa kemampuan pelaku pemberdayaan masyarakat di sekitar kawasan hutan masih rendah terlihat dengan tingginya eksploitatif terhadap hutan dapat mengancam kelestarian hutan itu sendiri. Hal tersebut sejalan dengan maraknya kegiatan penebangan liar (illegal logging) yang dilakukan oleh masyarakat.
\end{abstract}

Kata kunci: Sosialisasi Masyarakat, Sub Aliran Sungai, Kawasan Hutan

\section{Community Outreach on Sub-Streams Around the Forest Area of Klaben Village, Mariat Gunung District, Sorong Regency}

\begin{abstract}
The socialization of the Klaben Village Community by directly observing the local community about the Community's Attitude towards Community Empowerment in the management of the watershed, it is necessary to know the purpose of this socialization to know the socio-economic condition of the community towards natural resources around the sub-watershed. The method used in this community service is counseling at the community level with data that includes descriptive descriptions of the natural conditions of the community towards watershed management, so that the results of direct socialization to local communities who are active in doing plantations and taking firewood on the riverbank as a necessity live, and invite the community to be involved in planting 1000 trees on the riverbank. The conclusion is that the local community around Das shows that the ability of actors to empower communities around forest areas is still low, as seen by the high exploitation of the forest which can threaten the sustainability of the forest itself. This is in line with the rampant illegal logging activities carried out by the community.
\end{abstract}

Keywords: Community Socialization, Sub-River, Forest Area

\section{PENDAHULUAN}

Masyarakat dalam yang di kategorikan sebagai masyarakat local, masyarakat adat adalah kesatuan elemen yang berperan penting dalam pengelolaan kawasan hutan agar tetap lestari. Serta dalam mengelola kawasan aliran sungai yang ada disekitar hutan untuk 
selalu mengingatkan elemen yang berkepentingan didalan kawasan tersebut diataranya keaktifan instansi terkait dan masyarakat dalam mengelola kawasan aliran sungai dan hutan yang lebih baik, memberikan kepastian kedepan bahwa kondisi lahan yang produktif sesuai dengan daya dukung dan daya tampung lingkungan aliran sungai dan kawasan hutan yang saling terkait secara berkelanjutan, mewujudkan harapan kuantitas, wujud kualitas dalam ketersediaan air yang optimal secara ruang dan waktu serta wujud peningkatan kesejahteraan taraf hidup masyarakat.

Dalam hal mengelola suatu kawasan sangat diperlukan pedoman bagi perencanaan pembangunan keberlanjutan kawasan tersebut. Tujuan dari hal tersebut yakni agar tata lingkungan hidup dan pemanfaatan sumber daya alam hayati dapat dilakukan secara tertib, efisien, dan efektif. Terjangkau tanpa harus merusak kawasan tersebut. Pelaksanaan pembangunan, penggunaan sumber daya alam hayati dan air dilakukan secara terencana, rasional, optimal, bertanggungjawab, dan sesuai dengan kemampuan daya dukungnya dengan mengutamakan kemakmuran rakyat dalam yand didalamnya antara lain masyarakat lokal. Di samping itu, harus memperhatikan pula kelestarian fungsi kawasan hayati dan air, keseimbangan lingkungan hidup dan keanekaragaman hayati guna wujudkan pembangunan yang berkelajutan (Asdak, 2012)

Sungai memiliki peran penting dalam mencapai strategis sebagai salah satu sumber daya alam hayati dan konservasi tanah dan air yang mendukung kehidupan masyarakat. Peranan sungai di dalam konteks perkotaan menjadi sangat penting, khususnya dalam upaya mempertahankan sumber daya air yang berkelanjutan. Pengelolaan Daerah Aliran Sungai (DAS) merupakan salah satu aspek dari Pengelolaan Sumber Daya Air (PSDA) pada suatu Wilayah Pengembangan Sumber Air (WPSA) yang merupakan upaya pendayagunaan sumber-sumber air secara terpadu dengan upaya pengendalian dan pelestariannya (Suganda dkk, 2009).

Masyarakat yang memiliki rasa memiliki dengan penuh kesadaran, jiwa motivasi yang tinggi akan mampu menjadi masyarakat yang bijaksana serta dapat menciptakan lapangan kerja sendiri dan melakukan perubahan yang positif terhadap lingkungannya (Karliati dkk, 2005).

Masyarakat Kampung Klaben merupakan Masyarakat pelaku pemberdayaan dalam 
penegelolaan DAS dimana Kampung Klaben merupakan daerah yang berbatasan langsung pada Kawasan Hutan dan Sub DAS Klajolo dengan masyarakat yang aktif berinteraksi disekitar Sub DAS Klajolo dengan luas 850,38 Ha, Sub DAS Klajolo termasuk dalam DAS Klamatu yang terdiri dari beberapa sungai-sungai besar diantaranya DAS Warsamson, DAS Beraur, DAS Sedine dan DAS Seget (Peta DAS Papedda Kabupaten Sorong, 2014).

Masyarakat Kampung Klaben sebagai Pelaku dalam hal pemberdayaan masyarakat di sekitar hutan diharapkan memiliki kemampuan, sikap dan keterampilan yang memadai dalam mengarahkan masyarakat sekitar yang tidak terlibat langsung dengan kawasan DAS dalam menjalankan kegiatan yang berkaitan dengan pelestarian hutan dan pembebasan masyarakat dari belenggu ketidakberdayaan dan kemiskinan. dimana diketahui bahwa peran Masyarakat sekitar das menunjukkan bahwa kemampuan pelaku pemberdayaan masyarakat di sekitar kawasan hutan.

\section{METODE}

Metode pelaksanaan pengabdian masyarakat ini dilakukan dengan cara penentuan masalah melalui proses identifikasi masalah berdasarkan observasi lapangan dan wawancara dengan masyarakat. Kemudian dilakukan solusi pemecahan masalah melalui peningkatan kapasitas masyarakat local sebagai peran masyarakat dalam memanfaatkan sumberdaya hutan disekitar Sub DAS dalam mengantisipasi berbagai keadaan yang berbeda-beda di sepanjang Sub aliran sungadi sekitar kampung Klaben dengan membahas persepsi dan sikap masyarakat di sekitar hutan dan wilayah sungai melalui kegiatan penyuluhan.

\section{HASIL DAN PEMBAHASAN}

Kegiatan Pengabdian ini dilaksanakan melalui penyuluhan kepada masyarakat pada tanggal 27 Januari 2020 bertempat di balai kantor kampung Klaben Distrik Mariat Gunung. Kegiatan yang dilaksanakan selama 1 bulan dan metode yang di gunakan dalam pengabdian ini adalah penyuluhan pada tingkat masyarakat dengang data yang mencakup deskriptif yang menggambarkan suatu kondisi alam masyarakat terhadap daerah aliran sungai. Penyuluhan ke dua akademisi ini di bagi dalam 4 (empat) sesi kegiatan; (1) Penyuluhan langsung ke masyarakat lokal yang aktif melakukan perkebunan dan 
pengambilan kayu bakar di are pinggiran sungai untuk kebutuhan rumah tangga. (2) Penyuluhan dini di tingkat SMP dan SMA pentingnya menjaga lingkungan. (3) Kegiatan Penyuluhan pada masyarakat kampung klaben distrik mariat gunung kabupaten Sorong. (4) Kegiatan ini adalah kegiatan penanaman 1000 pohon pada pinggiran sungai oleh masyarakat setempat. Dapat di lihat pada gambar penyuluhan di bawah ini dengan begitu antusianya masyarakat menerima kami sebagai penyuluh di kampung mereka

1. Penyuluhan langsung ke masyarakat local yang aktif melakukan perkebunan di pinggiran sungai serta mengambil kayu bakar di pinggiran sungai sebagai kebutuhan hidup

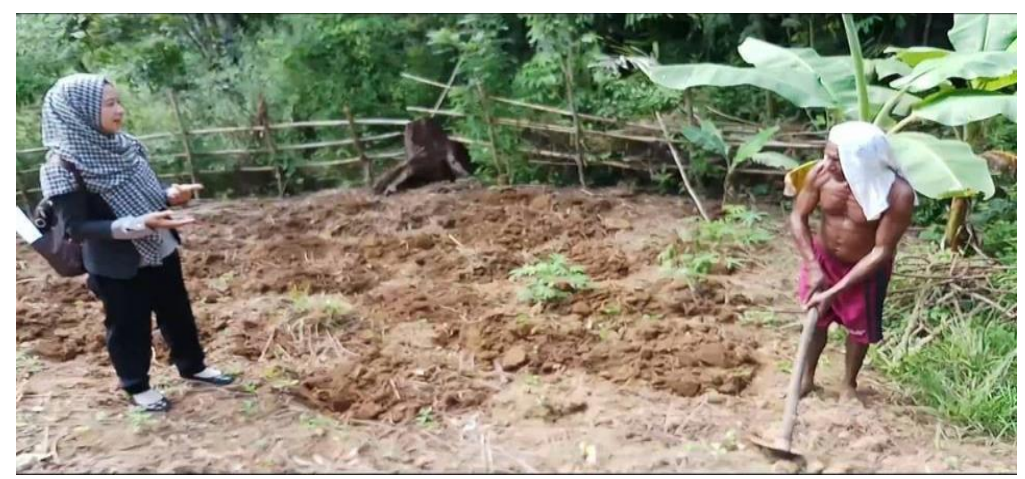

Gambar 1. Penyuluhan Terhadap Masyarakat Lokal

2. Penyuluhan pada usia dini di tingkat SMP dan SMA mengajak ikut berperan penting dalam menjaga lingkungan dalam hal ini kebersihan sungai dan lingkungan sekitar sekolah dengan tidak membuang sampah di sembarang tempat. Contoh nyata yang bisa di tanamkan dari awal bahwa perlunya mencintai kebersihan mulai dari diri kita sendiri. 


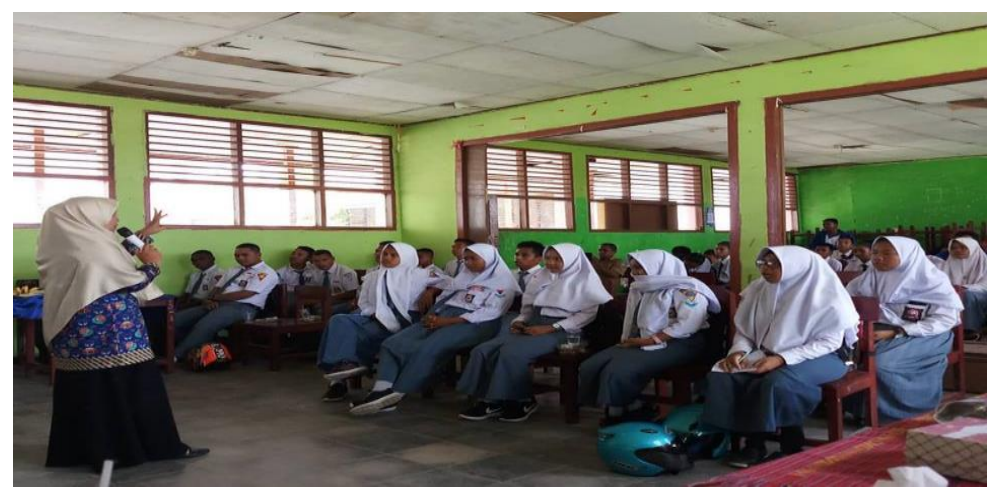

Gambar 2. Penyuluhan di SMP dan SMA

3. Kegiatan penanaman 1000 pohon pada pinggiran sungai oleh masyarakat kampung klaben distrik aimas. Mengajak masyarakat agar tetap saling mengisi dan jangan membiarkan kawasan areal tempat tinggal kita kosong tanpa ada naungan pohon didalamnya sebagai sumber kehidupan yang akan di butuhkan pada diri kita, anak-anak kita bahkan sampai cucu kita untuk slalu mencintai adanya pepohonan disekitar rumah sebagai tempat berlindung, dan menciptakan kawasan yang sejuk kaya akan oksigen.

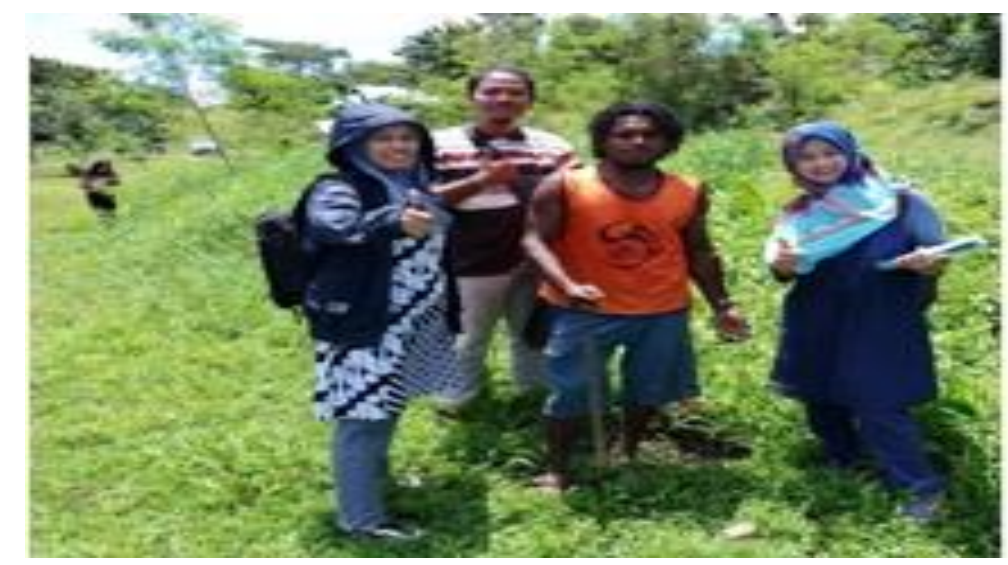

Gambar 3. Kegiatan Penanaman Pohon

Selain dari itu, dari pengabdian ini kami tim penyuluh juga melakukan penyebaran kuisioner untuk memotret persepsi masyarakat terhadap kawasan hutan disekitar sub aliran sungai kampung Klaben. Akses jalan telah dibangun untuk kebun masyarakat yang berada pada kawasan hutan berbatasan dengan aliran sungai serta dapat kita lihat bahwa tutupan lahan didominasi oleh perkebunan dan semak belukar akibat pembukaan lahan hutan, dari temuan riset itu menunjukan $56 \%$ (persen) berada pada tingkat kategori baik dalam mengetahui pentingnya aliran air dalam kehidupan pertanian dan menambah perekonomi masyarakat dalam bercocok tanam di sekitar hutan ditandai dengan skor 350, sedangkan $22,4 \%$ (persen) berada pada tingkat pemahaman sedang dengan skor 84 . 
Dapat dilihat pada gambar dibawah ini mengingat selama penyuluhan berlangsung respon masyarakat sekitar kawasan dalam pengelolaan aliran sungaisangat tinggi.

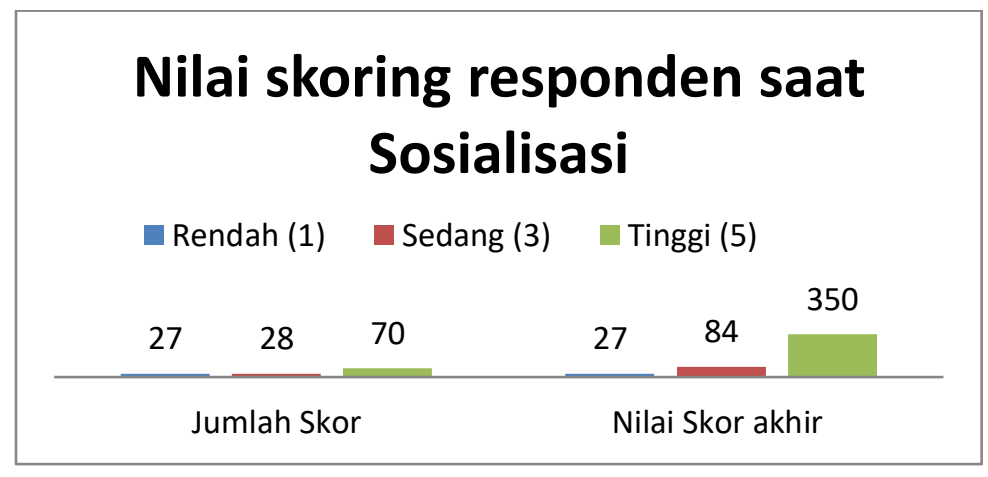

Gambar 4. Nilai Skoring Responden

Tetapi menjadi catatan penting untuk kita sebgai tim penyuluh dan kepada masyarkat, dari pengabdian ini adalah mayoritas masyarakat menyatakan bahwa hutan sangat mampu berpengaruh terhadap kondisi lingkungan di sekitar daerah aliran sungai serta sangat mampu mencegah terjadinya erosi bencana alam, longsor dan erosi tanah sedang perlu diketahui bahwa curah hujan dikawasan kota sorong papua barat sangat tinggi untuk menghidari itu perlunya hutan dan mencintai kawasan disekitar kita untuk tetap sadar mencintai lingkungan yang bersih. Sosial Ekonomi Masyarakat kampung Klaben dalam pengelolaan Sumberdaya hutan di sekitar Sub aliran sungai dipengaruhi oleh persepsi dan perilaku sebagai pendorong tingkat partisipasi masyarakat dalam melakukan aktifitasi di sekitar sungai, ada beberapa faktor yang mempengaruhi tingkat persepsi yaitu tingkat pendidikan, mata pencaharian dan tingkat pendapatan.

\section{SIMPULAN}

Manfaat dari sosialisasi masyarakat tentang pengelolaan sub aliran sungai di sekitar hutan kampung Klaben diketahui bahwa hutan mampu berpengaruh terhadap kondisi lingkungan serta mampu mencegah terjadinya bencana alam, serta diketahui ternyata tingginya eksploitatif terhadap hutan disekitar aliran sungai dapat mengancam kelestarian kawasan itu sendiri. Hal tersebut terlihat mobilisasi truk pengangkut kayu begitu tinggi dengan mengindikasikan bahwa maraknya kegiatan penebangan liar (illegal logging) saat ini yang dilakukan oleh masyarakat diluar yang mengambil keuntungan dari masyarakat lokal. Sedangkat tingkat partisipasi masyarakat yang ikut ambil bagian dari sesi sosialisasi ada beberapa faktor yang mempengaruhi tingkat persepsi yaitu tingkat pendidikan, mata 
pencaharian dan tingkat pendapatan.

\section{UCAPAN TERIMAKASIH}

Terima kasih kepada Direktorat Riset dan Pengabdian Masyarakat Direktorat Jenderal Penguatan Riset dan Pengembangan Kementrian Riset, Teknologi dan Pendidikan Tinggi atas Bantuan Dana Skema Pegabdian Kepada Masyarakat Stimulus yang telah kami terima untuk Tahun Pendanaan Tahun 2019. Serta kepada Pihak LPPM UMSorong yang selalu mensupport tim dosen untuk meningkatkan karya ilmiah dan pengabdian kepada masyarakat diantara jejaring dosen peneliti.

\section{DAFTAR PUSTAKA}

Asdak. C. (2012). Hidrologi dan Pengelolaan Daerah Aliran Sungai. Gadjah Mada University Press. Yogyakarta

Akib, M., Irnawati, I., \& Ibrahim, I. (2019). Seminar Greenschool: Sekolah Peduli Lingkungan Hijau untuk Siswa SMA/SMK dan SMP. Abdimas: Papua Journal of Community Service, 1(2), 1-5.

Maruapey, A., \& Irnawati, I. (2019). Studi Sekuestrasi Karbon Pada Tegakan Jati (Tectona grandis Linn.) Di Areal Penghijauan Kabupaten Sorong. Median: Jurnal Ilmu Ilmu Eksakta, 11(1), 26-38.

Fuady Z, Azizah C, (2008). Tinjauan Daerah Aliran Sungai Sebagai Sistem Ekologi dan Manajemen Daerah Aliran Sungai.

Harini S, Suyono, Mutiara E, 2012. Manajemen Pengolahan Lahan Kritis Pada DAS Brantas Hulu Berbasis Masyarakat (Pilot Project Desa Bulu Kerto, Kota Batu.

Irnawati, I. (2019). Partisipasi Masyarakat Terhadap Pelestarian Hutan Cagar Alam Di Kampung Saporkren Distrik Waigeo Selatan Kabupaten Raja Ampat. Median: Jurnal Ilmu Ilmu Eksakta, 10(1), 28-38.

Karliati B, Hj Retnowati R, Suhardi E, (2005). Community Empowerment through Toyota's Forest Program to Establish Environmental Care Community.

Mahbub MAS, (2007). Penyuluhan Kehutanan Partisipatif. Fahutan Kehutanan, Universitas Hasanuddin. 
Ngabiyanto. (2004). Persepsi dan sikap masyarakat desa hutan terhadap lahan hutan pascapenjarahan di Kabupaten Blora. Jurnal Litbang Provinsi Jawa Tengah, 2(2), $153-62$ 